\title{
Design e arte: processos híbridos na representação da paisagem na pintura do início do século XXI
}

\author{
Design and art: hybrid processes in the landscape's representation in the painting of \\ the twenty-first century
}

SILVA, Francis Rodrigues; Especialização em História da Arte Moderna e Contemporânea - EMBAP; Programa de Pós-Graduação em Tecnologia e Sociedade (PPGTE/UTFPR)

frsctba@gmail.com

SILVEIRA, Luciana Martha; Doutora em Comunicação e Semiótica - PUC-SP; Programa de PósGraduação em Tecnologia e Sociedade (PPGTE/UTFPR)

silveira.lucianam@gmail.com

\section{Resumo}

O artigo trata da relação entre o design e a pintura, apresentando como a imaginação gráfica, com procedimentos vindos da colagem tais como a sobreposição e a justaposição de fragmentos, produzem outras formas de representação da paisagem na pintura no século XXI. Século este que apresenta um grande fluxo de informações na vida cotidiana, através dos meios de comunicação, tais como a internet, a televisão, cinema e fotografia e pela produção do design. Diante desse caos notável no mundo atual, são percebidos processos híbridos que geram e coordenam narrativas e imagens esquizofrênicas. Tudo acontece simultaneamente, carregando ambiguidades, heterogeneidades e contradições. A pintura de paisagem, mesmo sendo um meio mais tradicional, pode dialogar com essas questões. Desse modo, tanto o design quanto a pintura têm características híbridas, em que diferentes práticas e procedimentos são combinados, articulando assim a linguagem, signos e imagens.

Palavras Chave: design; arte; pintura; imagem.

\begin{abstract}
The article deals with the relation between the design and the painting, presenting the graphic imagination, which has procedures from the collage, such as the overlap and the juxtaposition of fragments, and it produces other forms of representation of the landscape in the painting in the 21st century. This century presents a great flow of information in everyday life, through the media, such as the internet, television, film and photography and the production of design. Faced with this remarkable chaos in today's world, hybrid processes are perceived and generate and coordinate schizophrenic narratives and images. Everything happens simultaneously, carrying ambiguities, heterogeneities and contradictions. The landscape's painting, even though it is a more traditional medium, can dialogue with these questions. In this way, both design and painting have hybrid characteristics, in which different practices and procedures are combined, thus articulating language, signs and images.
\end{abstract}

Keywords: design; art; painting; image. 


\section{Introdução}

Este artigo busca refletir sobre a relação do design com a arte, evidenciando como alguns procedimentos estéticos oriundos da colagem são utilizados na representação da paisagem na pintura produzida no século XXI. Sendo assim, o design é considerado aqui como uma atividade com cenários amplos e interdisciplinares em que processos e elementos são apropriados e sintetizados em busca de se materializar imagens em diferentes meios artísticos, tais como a pintura.

Para isso, foi realizada uma pesquisa bibliográfica e pictográfica em que foram levantados marcos conceituais sobre o design, a partir de Rafael Cardoso Denis, assim como também foram consideradas questões dos estudos sociais de autores como Stuart Hall, García-Canclini e Jesus Martín-Barbero, afim de compreender relações entre a representação, a hibridação e a mediação das tecnologias neste contexto. Para o entendimento de questões sobre a relação entre imagem e tecnologia foram observados os pontos de vistas de Arlindo Machado.

O design nos últimos anos tem se estabelecido como atividade de pesquisa, trabalho e criação, em que são combinados aspectos de concepção e de projeção, assim como a relação com o arranjo, com a estrutura e a configuração de algo (DENIS, 2002). Segundo Denis, o design opera em dois níveis que atribuem conceitos e dão forma material $(2002$, p.16), se relacionando e se misturando com outras áreas, tais como a arquitetura, a engenharia e as artes, podendo ser um campo que apresenta características interdisciplinares e híbridas.

O híbrido, conforme García-Canclini (2003, p.XIX), pode ser pensado como processo de construção sociocultural, em que objetos e práticas se combinam e geram outras estruturas. Sendo assim, as relações de sentido se constroem e reconstroem nas misturas, nas transformações culturais e nas relações de mediação com a tecnologia (GARCÍA-CANCLINI, 2003, p. XXIV). Desse modo, o design pode ser pensado como uma atividade de hibridação, que incorpora outras, a partir dos diversos processos que envolvem formas de representação, mediação e a tecnologia.

O design se insere no tempo e lugar onde é produzido, construindo e desconstruindo representações. Conforme Stuart Hall (2016, p.31), a representação se relaciona com práticas que produzem a cultura por meio da linguagem, meio usado para se produzir significados que são compartilhados entre membros de um grupo ou sociedade. Assim, é importante entender que ao se produzir representações tudo aquilo que vivenciamos no cotidiano, nas práticas sociais, na relação entre o artefato e o simbólico está sendo articulado. Neste espaço de produção e compartilhamento de significados, pode-se constatar que as coisas em si, os artefatos, não têm um significado único, fixo e inalterável e são recriados constantemente nas relações sociais. De acordo com Stuart Hall (2016, p.20), os significados também estabelecem como se dão as práticas sociais, influenciando condutas que geram efeitos.

Através das experiências vividas no cotidiano, pode-se então considerar o conceito de representação dado por Stuart Hall (2016) e fazer relações com a pintura de paisagem produzida atualmente. A pintura seria uma representação a partir de imagens (figurativas ou abstratas), que expressa e transmite pensamentos, conceitos e símbolos através da materialidade, por exemplo da tinta, e da superfície de um suporte, como a da tela.

A pintura de paisagem se firmou ao longo da história da arte como um gênero artístico, 
que representa no meio pictórico a relação do homem com o mundo, com a natureza e com o espaço (CAUQUELIN, 2007, p.35). ${ }^{1}$ Contudo, no decorrer do tempo, houve modificações no gênero, apresentando diferentes significados, em variados tipos de representações, assim criando novos sentidos que se relacionam com as mudanças culturais, sociais, tecnológicas e científicas.

\section{O design gráfico e o início do século XXI}

No início do século XXI percebe-se na vida urbana uma forte e importante vinculação com a comunicação nas transmissões e estabelecimento de redes. Este contexto pode ser percebido na fluidez da experiência cosmopolita e suas mediações (MARTíN-BARBERO, 2004 p.11). Segundo Martín-Barbero (2004, p.37), essas questões vividas no cotidiano nos proporcionam alterações perceptivas na experiência espaço-temporal, através dos fluxos de comunicação e informações, da desagregação social e da fragmentação vivenciadas nas cidades e nas imagens. Por meio de outras possibilidades de relações com o mundo, nas fronteiras ambíguas e nem sempre delineadas, e a construção de representações e identidades através de meios de comunicação, é evidente a materialização destas mudanças no cotidiano, o que acaba atenuando os limites entre a informação e o saber, assim como da imaginação e da razão (MARTíN-BARBERO, 2004, p.36).

As mudanças são visíveis nas mais diversas experiências: as viagens, os fluxos migratórios de cruzamentos de fronteiras, a diversidade das cidades da América Latina, a arquitetura, o caos e os fenômenos transitórios. (CANCLINI, 2003, p. 285). Também observamos processos híbridos nas próprias experiências mediadas pelos meios de comunicação, como a Internet, a televisão, o cinema, a fotografia, as colagens publicitárias fragmentadas, que segundo Canclini geram narrativas esquizofrênicas que coordenam as múltiplas temporalidades de diferentes espectadores. Vale também destacar a linguagem do videoclipe, muito presente na comunicação dos dias de hoje, descontínua e acelerada, percebida através da justaposição e de outro tipo de organização dos dados, com fragmentos de imagens de todas as partes e visões efêmeras (CANCLINI, 2003, p. 306).

Assim como Canclini e Martín-Barbero, Denis (2002, p. 212) também evidencia como na experiência do início do século XXI, as visões se dão de modo fragmentado, sendo recompostas na mente dos indivíduos de forma passageira. Na internet e na televisão a velocidade e abundância de informações possuem sobrevida, tudo é muito rápido. É perceptível um processo de fragmentação e sobreposição de imagens no cotidiano que se dão pelo excesso, pela poluição visual e a saturação pela publicidade, sendo o olhar tratado como um modo de consumir (DENIS, 2002, p.212).

O design também carrega esses fragmentos e dialoga com o mundo. Desde meados do século XX, a publicidade é um fenômeno cultural e econômico que junto com o design, é usada nos meios de comunicação tais como revistas, jornais, televisão, sites de internet entre outros, como maneira para estabelecer relação com o consumidor criando uma rede de associações e atividades que geram imagens (DENIS, 2002, p.183).

Segundo Denis (2002), ao tratar especificamente do design gráfico, nota-se como a atividade está inserida nas práticas cotidianas, na comunicação visual e no modo como as informações são apresentadas e organizadas, nos meios impressos, tais como livros, jornais,

\footnotetext{
${ }^{1}$ Segundo Cauquelin, a origem do gênero se dá por volta de 1425 na Europa, sendo fortemente usada a perspectiva como meio de representação (2007, p.35).
} 
cartazes, revistas, embalagens e nos digitais. O design e a comunicação visual realizam o cruzamento de dados, de ordem econômica e cultural atuando com a tecnologia e também com a arte, lidando com diferentes imagens, repertórios e regimes visuais (DENIS, 2002, p.49). Junto com a fotografia, percebe-se a produção, reprodução, veiculação e a circulação de imagens, que carregam modos de ver o mundo, por meio de composição e enquadramentos (DENIS, 2002, p.55). Desde os anos de 1960, influenciado pela Pop art, o design estabelece relação com a moda e com a arte, trazendo modos de representar e se apropriar de diversas fontes, inclusive as históricas, valorizando a individualidade e estilos de vidas (DENIS, 2002, p.181).

Conforme Denis (2002), no design gráfico, por meio da tecnologia, percebem-se diversos processos que permitem fragmentar elementos criando outras combinações, fazendo parte da imaginação gráfica:

Toda uma sequencia de técnicas e processos para a manipulação de texto e imagem - que inclui a litografia, a rotogravura, o fotolito, o offset e outros recursos gráficos tradicionais - já envolvia a possibilidade de fragmentar e recompor núcleos de informação preexistentes em novas combinações. Pode-se dizer, na verdade, que a sobreposição e a recombinação de elementos são princípios básicos da imaginação gráfica, pelo menos desde a primeira colagem ou da primeira história em quadrinhos. $O$ fato do projeto gráfico já possuir, por definição, essa predisposição para lidar com o fragmento e a sequência tem contribuído para alterar o modo sutil o equilíbrio interno do campo do design nos últimos anos (p. 212 - 213).

No design gráfico produzido no final do século XX e no início do século XXI, segundo Denis (2002, p.213-214), percebem-se transformações conceituais, com a substituição de questões funcionalistas para uma visão eclética e híbrida. Nas produções e representações são usados a desordem, o ruído e o excesso e aquilo que está sendo criado deve ser compreendido como a junção de diferentes partes, em que se misturam forma, função, técnicas e materiais, existindo a reprodução e a apropriação de imagens. Denis destaca a produção de designers tais como Neville Brody (Figura 1), April Greiman (Figura 2) e David Carson (Figura 3) que já na década de 1980 e 1990 dialogavam com esses tipos de questões, em que o excesso e o caos eram usados em peças gráficas (DENIS, 2002, p.214).

Verifica-se assim o pensamento de uma época, que se relacionam com outros paradigmas de estilo, que podem ser tanto manuais como também dialogar com as tecnologias digitais, existindo outros modos de se tratar a imagem, a diagramação e a tipografia por meio do computador, de sistemas operacionais (Mac, Windows ...) e softwares (Ilustrador, Photoshop, CAD, CorelDraw). Trabalhar com esses elementos se tornou mais fluido e simples, por meio da manipulação de fontes e de suas características que antes faziam parte do trabalho do tipógrafo (DENIS, 2002, p.214). Existe um novo jeito de se proceder e se relacionar com a tecnologia, em que é trazido a metáfora do navegar, por meio de uma experiência fragmentada da pósmodernidade (DENIS, p.215).

Pensando sobre a relação do design e as tecnologias tratados por Denis (2002), percebe-se o diálogo com questões trazidas por Martín-Barbero (2004, p. 36) que amplia o significado de tecnologia que não remete somente as máquinas, mas também aos novos modos de percepção e de linguagem que apresentam novas sensibilidades. 
Figura 1 - Neville Brody

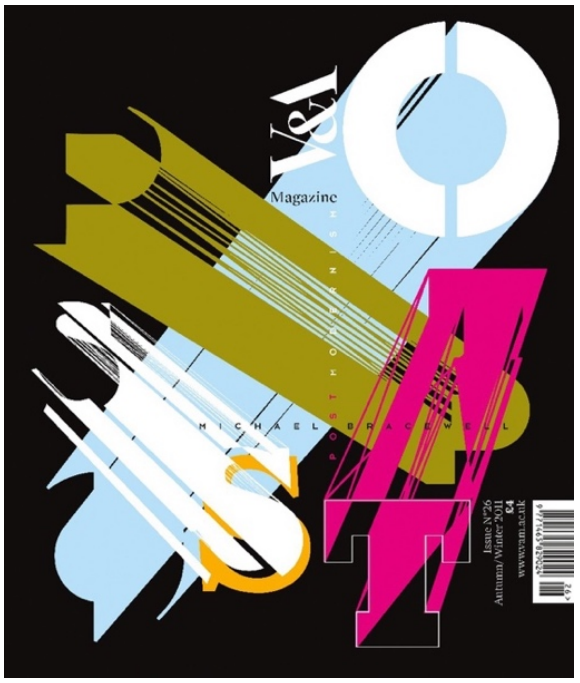

Fonte: Lürzer's Archive (2018)

Figura 2 - April Greiman

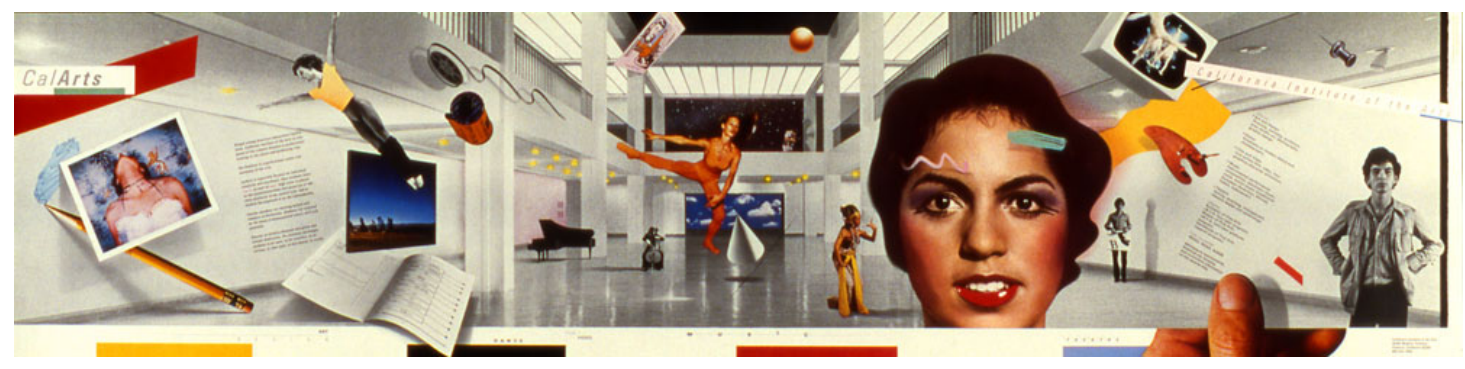

Fonte: Made in Space (2018)

Figura 3 - David Carson

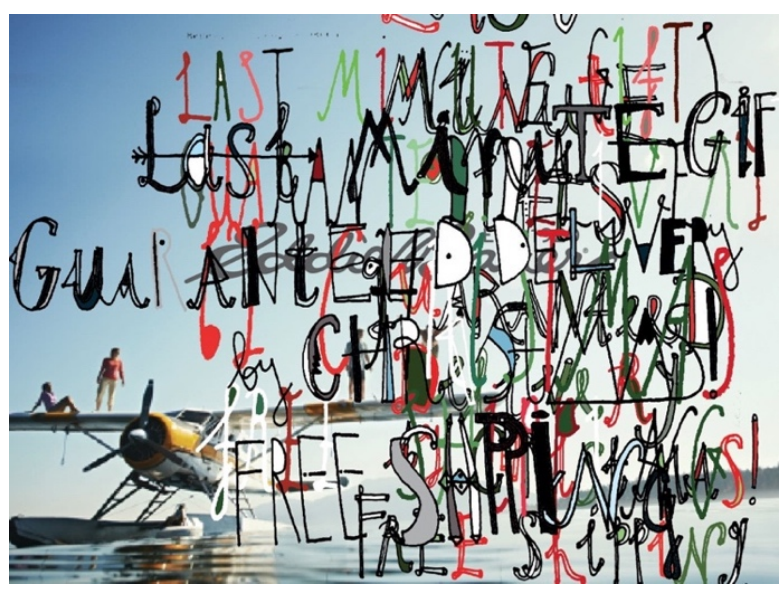

Fonte: David Carson Design (2018) 
Considerando os procedimentos da imaginação gráfica no design gráfico, que trabalha com fragmentos e arranjos combinatórios por meio de justaposições e sobreposições, é possível criar ligações com questões levantadas pela cultura digital ou cibercultura, em que as relações dos seres humanos se dá pela mediação entre tecnologias e comunicações digitais. ${ }^{2}$

Segundo Lemos (2005), a partir da relação entre as tecnologias, os meios de comunicação e informação, podemos entender a cultura contemporânea, em que são visíveis práticas em que informações, textos, sons, músicas e imagens são trabalhados por meio de colagens, montagens e combinações (remix, cut and past). Outro aspecto importante, é que a "re-mixagem" e a recombinação fizeram parte das vanguardas artísticas do século XX, tais como o cubismo, e desde a segunda metade deste século passaram a ser amplamente utilizadas na cultura ocidental (LEMOS, 2005, p.3). O que ocorre é que muitas práticas de criação acabam sendo repensadas, mesmo as mais tradicionais, mas não substituídas (LEMOS, 2005, p.3).

Desse modo, é possível compreender que os procedimentos apresentados e utilizados principalmente no design gráfico fazem parte do imaginário de uma época, de uma forma de se organizar os diversos tipos de informações. Esta forma de pensar não está inserida só no design ou nos trabalhos digitais, mas também podem ter contaminações em meios mais tradicionais tais como a pintura sobre tela que será tratada a seguir.

\section{Pintura, paisagem e fragmento}

Em um mundo repleto de informações, com milhares de imagens que são geradas, reproduzidas e apropriadas diariamente por meio dos meios de comunicação, verifica-se a existência de trabalhos de pintura com a saturação de informações. São imagens, tais como aquelas vividas em meios como a Internet, a televisão, o cinema, os videoclipes, a fotografia, as criações publicitárias e montagens do design. Segundo Machado, as tecnologias, os aparelhos e os processos envolvidos atuam "em nossos sistemas de vida e de pensamento em nossa capacidade imaginativa e nas nossas formas de percepção do mundo." (MACHADO, 2001, p.10). Dessa maneira, as vivências dos meios de comunicação se desdobram em diferentes mídias, inclusive na pintura.

As práticas citadas anteriormente do design gráfico, tais como a da fragmentação, da colagem e da montagem estão presentes nas imagens do cotidiano, demonstrando um modo de se tratar e organizar o visual. É sabido que a prática da colagem foi amplamente usada principalmente nas experimentações artísticas no início do século $\mathrm{XX}$, tais como as de Pablo Picasso (Espanha, 1881 - 1973) com o papier collé (Figura 4), que fez uso de fragmentos de imagens que já existiam (GIANNOTTI, 2009, p.42). No início do século XXI, essas questões continuam sendo incorporadas ao uso das imagens.

\footnotetext{
${ }^{2}$ Conceito de Cultura Digital. Disponível em: http://culturadigital.br/conceito-de-cultura-digital/. Acesso em: 25 de março de 2018.
} 
Figura 4 - Pablo Picasso, Guitare, journal, verre et bouteille, 1913, papéis impressos e tinta sobre papel, 46,7 cm X $62,5 \mathrm{~cm}$

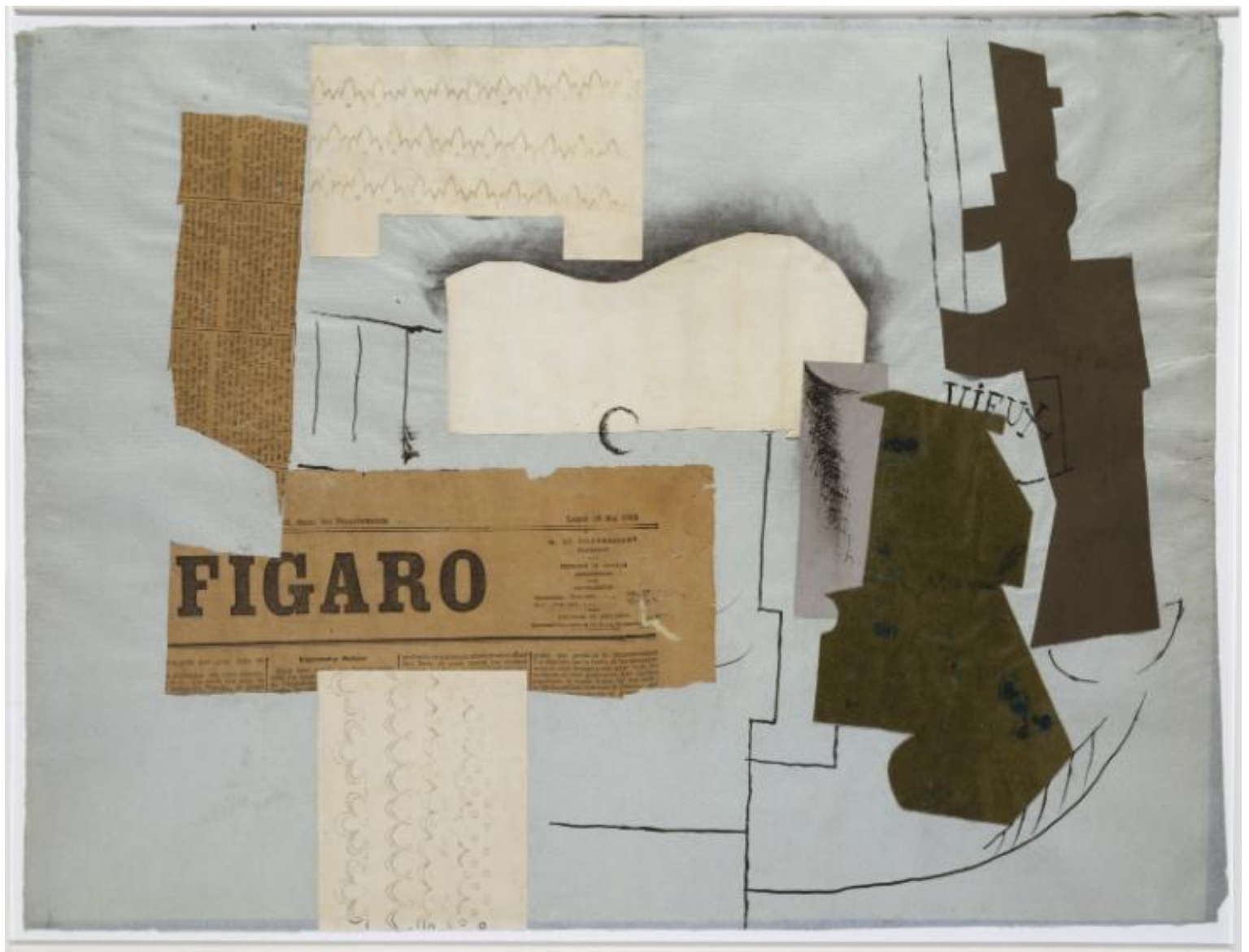

Fonte: TATE (2018)

$\mathrm{Na}$ produção atual de pintura, percebe-se que existem artistas que se apropriam de elementos visuais do cotidiano, da cultura pop e das diversas mídias, fazendo uso da colagem, de princípios da montagem e da edição, tanto usando o computador como trabalhando diretamente com elementos de forma manual. Esta produção apresenta imagens caóticas que rompem com a relação entre figura e fundo através da fragmentação trazendo outros modos de representar o espaço e o cotidiano a partir do entrecruzamento de ideias. Existe uma polifonia de possibilidades que carrega vestígios de diferentes momentos artísticos da história da arte (COELHO, DIEGUES, 2011).

Para produzir pinturas, o artista pode juntar referências e ter uma coleção de imagens, com fotografias, peças de design gráfico e propagandas, ilustrações, cenas de filmes e referências de obras de arte (IWASSO. 2011, p. 9-10). Para então, operar com signos e significados com imagens de diversas origens, dessa maneira, a superfície da tela recebe acúmulo de fragmentos justapostos e sobrepostos sem hierarquia. (IWASSO, 2011, p. 46). As obras produzidas apresentam imagens que se dão por processos de associação, que geram ambiguidades, situações polissêmicas e que remetem a estrutura do labirinto que é intricada e descentrada, tais como o pensamento (ideias e memórias), o que Machado chama de hipermídia (MACHADO, 1997). 
O que ocorre nesse tipo de produção é a estética do excesso e da saturação, são montagens polifônicas que unem vários elementos e propiciam simultaneidade (MACHADO, p. 1997, 239). Existe um desdobramento da figuração e dos motivos clássicos, que proporcionam diferentes contextos espaciais e temporais. São geradas configurações híbridas que se encaixam e se encavalam (MACHADO, p. 1997, 240), agregando na pintura atual, diferentes meios expressivos tais como a fotografia e o desenho, e que podem ainda se relacionar com procedimentos do design gráfico.

A pintura também pode incorpora aspectos do design gráfico por meio da imaginação gráfica com técnicas e processos de manipulação da imagem. Existe assim, a possibilidade de fragmentar ou juntar diferentes partes para serem geradas novas combinações, tal como na pintura do artista brasileiro Luiz Zerbini (Figura 5). Seria um modo de se pensar as imagens usando seus fragmentos e fazendo a justaposição e a sobreposição para criar desordem, ruído e excesso. A pintura passa a existir por meio de colagens, de montagens e de combinações que trazem a ideia do remix e do cut and past. Assim como no design, a pintura acaba possuindo uma visão eclética e híbrida, em que diferentes estilos e tratamentos são incorporados em um trabalho.

Figura 5 - Luiz Zerbini, Mar do Japão, 2010, acrílica sobre tela, 2,90 m X 3,93 m

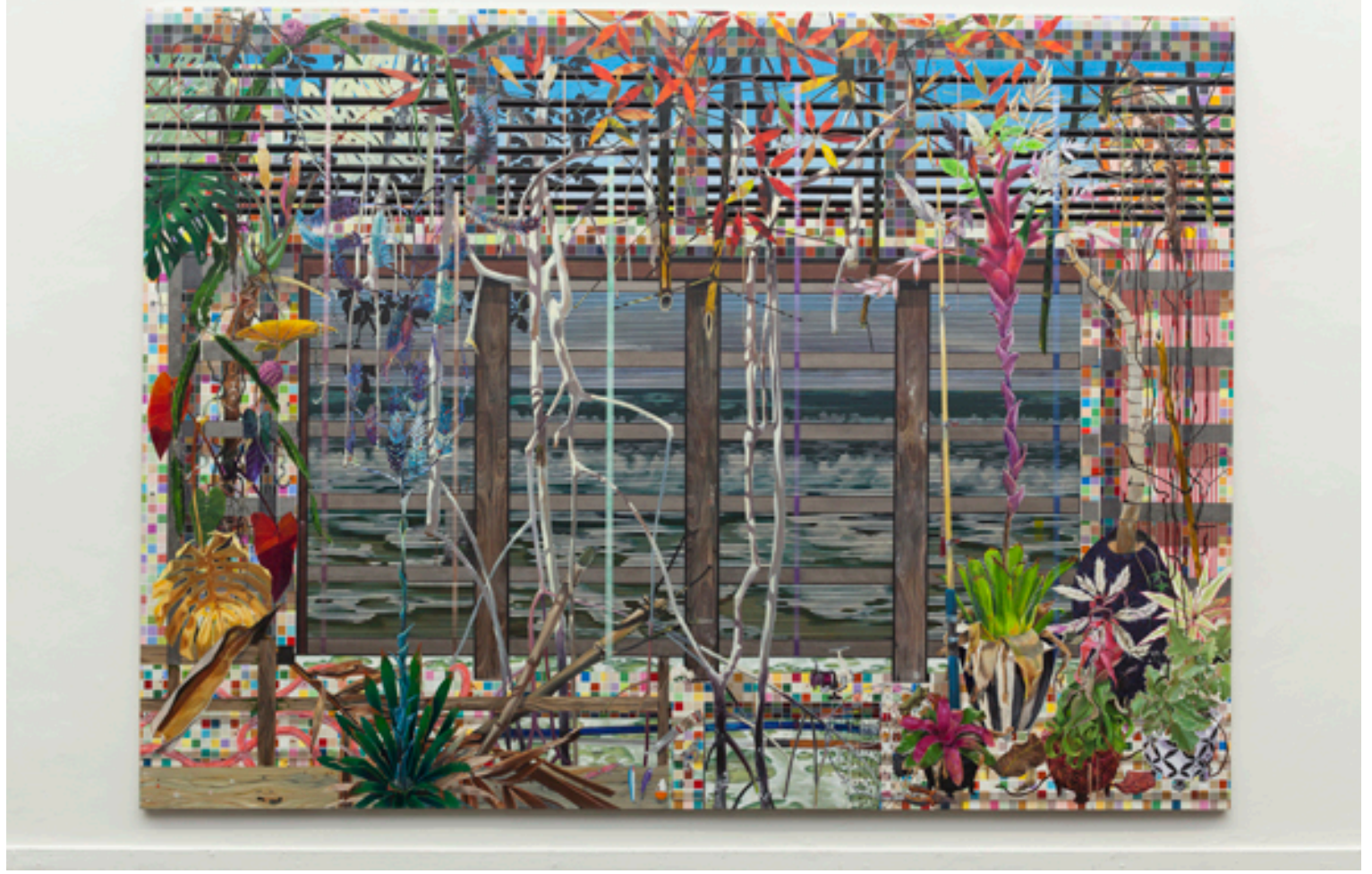

Fonte: Inhotim (2018)

Nas relações com a mídia, percebe-se mudanças na prática e no consumo de imagens mediadas por câmeras e computadores, com a manipulação digital das imagens (MACHADO, p. 
1997, 242) que acabam proporcionando o rompimento com modelos e cânones de representação herdados do Renascimento, tais como a perspectiva que busca representar o espaço de modo homogêneo e o figurativismo (MACHADO, p. 1997, 248).

É possível fazer associações entre os procedimentos utilizados no design para lidar com diferentes informações e os modos como os artistas pintores trabalham com a imagem. As tecnologias digitais, tais como os softwares usados no design gráfico, o Photoshop, llustrador e Corel Draw, entre muitos outros, também podem ser incorporados a produção artística. Contudo, o mais importante é que o conceito de se pensar a imagem que é trazido por essas ferramentas, também podem ser incorporados na produção manual. A questão não é só a ferramenta, mas o modo de se pensar. Arlindo Machado chama de "formas expressivas da contemporaneidade" (MACHADO, p. 1997, 236) os processos atuais na criação artística, e aponta a modificação da percepção humana do mundo por meio da influência de diversas tecnologias:

[...] novas sensibilidades, novos problemas de representação, novos conceitos estéticos e novas formas de compreender o mundo estariam sendo introduzidos em consequência da presença cada vez maior de recursos, processos e mediações tecnológicas na criação artística do nosso tempo. (p. 236-237).

Tratando especificamente desses tipos de trabalho que lidam com o caos, percebe-se um tipo de produção artística que dialoga com o gênero de pintura de paisagem, e que agrega diferentes elementos na sua representação. É possível notar que alguns artistas vêm desenvolvendo imagens da paisagem que se dá de modo diferente daquilo que já feito anteriormente. Estas obras trazem aspectos ambíguos e contraditórios na sua formalização como imagem e que se relacionam com a cultura, com a história, com a geografia e com a tecnologia.

Verifica-se como ao longo do tempo a representação da paisagem na pintura sofreu modificações. Os artistas trouxeram outras possibilidades de representação, influenciados por rupturas artísticas, culturais, tecnológicas e perceptivas (CAUQUELIN, 2007). Segundo Walter Benjamin: "No decorrer de longos períodos históricos, modifica-se não só o modo de existência das coletividades humanas, mas também a sua forma de percepção." (BENJAMIN, 2012, p.13).

Na produção atual de pintura é possível destacar a obra do artista Luiz Zerbini (São Paulo, 1959). Participante da geração brasileira de 1980, ele possui uma longa carreira, com uma produção diversificada com esculturas, instalações e pinturas. Em sua obra, além de apresentar trabalhos que se relacionam com o contexto abstrato, Zerbini também traz questões sobre a representação da paisagem (CAMPOS, 2017). Nestas obras são percebidos aspectos da edição de imagens e da colagem com a representação de elementos da natureza e da arquitetura urbana justapostos, remetendo ao caráter da improvisação da paisagem brasileira. 0 geométrico e o figurativo convivendo lado a lado. Na pintura de Zerbini se nota uma diversidade de estilos de representações, sendo que partes trazem um aspecto mais realista com a noção de ilusão de tridimensionalidade (luz e sombra) e outros possuem aspectos estilizados da forma, sendo tratados de maneira sintetizada (Figura 6). 
Figura 6 - Luiz Zerbini, Mamanguá - Recife, 2011, acrílica sobre tela, 2,93 m X 4,17 m

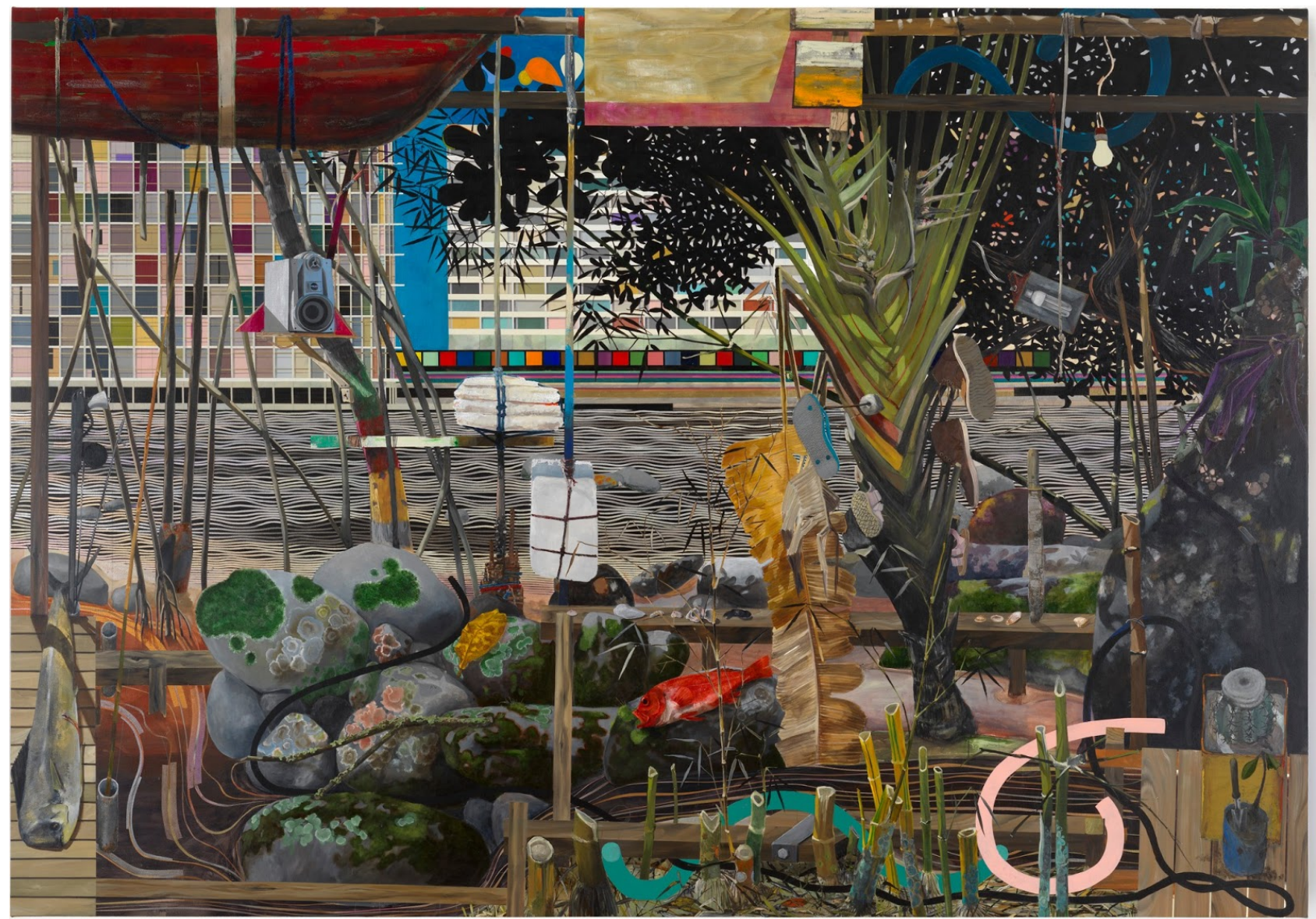

Fonte: BOL (2018)

Da Alemanha, é possível citar a obra do artista Franz Ackermann (Alemanha, 1963), que a partir de sua vivência no mundo, produz pinturas de um mundo globalizado tratando de outro modo a paisagem (Figura 7), mesclando a relação entre espaços reais e virtuais (GODFREY, 2009, p.213). Franz Ackermann parte de um modelo de representação estabelecido pelo gênero de paisagem, mas o que se visualiza são desdobramentos que apresentam questões e conflitos atuais, inclusive na maneira como a imagem é construída.

Estes artistas manipulam uma série de elementos para a representação de um tipo de paisagem em que são materializadas formas de ver o mundo (BERGER, 1999, p.12). Através dessas representações na pintura são compreendidas construções e mentalidades (BURKE, 2016, p. 123), modos de se tratar a imagem e de se pensar o entorno atualmente.

A partir do conceito de representação do autor Stuart Hall, é possível entender a pintura desses artistas como uma prática que produz e compartilha cultura através da linguagem (HALL, 2016) que possui um sistema de representação com imagens, que expressam pensamentos que também influenciam a percepção humana do mundo (BURKE, 2017, p.68). Todos esses conceitos, que se dão através da materialidade da tinta sobre a superfície da tela, demonstram formas de se conceber o espaço, algo que não se mantém fixo e é mutável ao longo do tempo. 
Figura 7 - Franz Ackermann, My Private Greens Leaving, 2014, óleo sobre tela,

$2,72 \mathrm{~m} \times 5,46 \mathrm{~m}$

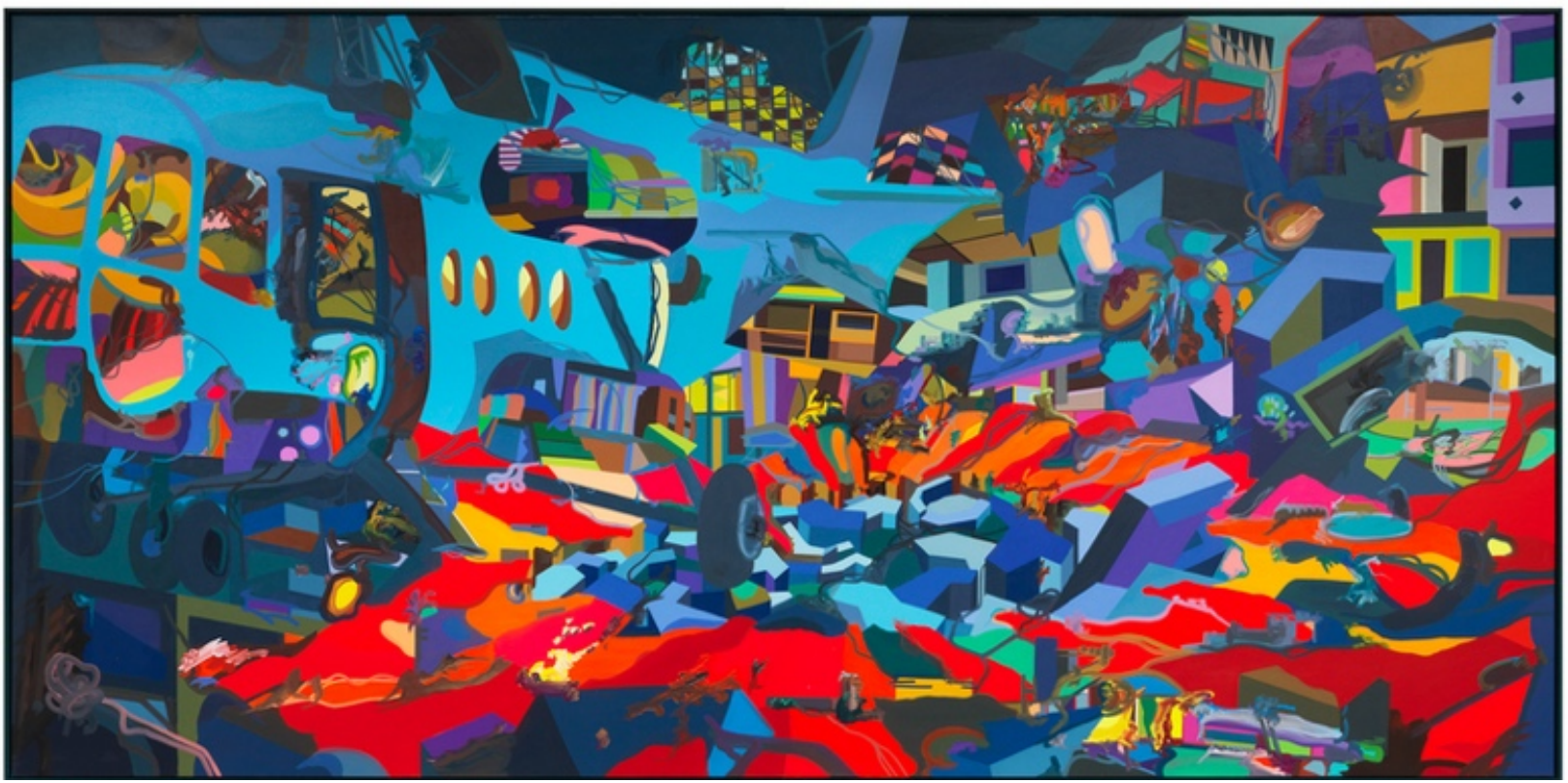

Fonte: White Cube (2018)

Existe uma tradição da pintura de paisagem e em cada momento da história diferentes criações foram materializadas pelo artista através de relações com seu próprio tempo, com a cultura, com a sociedade, com a tecnologia e com a própria arte. A imagem que representa a paisagem na pintura pode sofrer contaminações de outras linguagens como o design, o cinema, a fotografia, o conceito de edição e de recorte, tornando-se uma imagem híbrida. A pintura de paisagem produzida hoje traz uma temática que se relaciona e dialoga com aquela que foi produzida no passado. Estas obras com imagens fragmentadas não são o único modo de se tratar o espaço, existindo artistas que produzem pinturas que apresentam os modelos mais tradicionais de representação. Um modo de produção não exclui o outro.

Ao buscar compreender o fenômeno da produção da paisagem atual não basta apenas analisá-la por um único viés. A junção de diferentes áreas de trabalho e conhecimento, tais como o design, as artes visuais, a pintura, a fotografia e a comunicação tornam possível entender os embates entre o artista e sua produção fazendo uso dessa diversidade complexa. Na relação entre design e pintura para a representação da paisagem, o conceito de complexidade apresentado por Morin (2005 p. 6) pode ser tratado a partir da busca da articulação entre áreas disciplinares distintas, proporcionando assim um modo de trabalho e de articulação do conhecimento de modo multidimensional, ao invés de separá-las por meio de um pensamento simplificador. Conforme Morin (2005, p.35) nas interações podem existir fenômenos aleatórios e indeterminados que podem se relacionar com o acaso, com a tensão entre a parte e o todo, com o sentido de desordem e a busca de ordem.

Na pintura e no design existe uma relação de complementação, podendo ser pensadas juntas, de forma ambígua e contraditória devido as diferenças de natureza processual e de relação com a imagem. As experiências do mundo proporcionam o repertório de vivências dos artistas para a suas produções, mas essas obras também de alguma forma interferem nas visualidades e 
compreensões sobre tempo e espaço.

\section{Considerações finais}

Em um mundo que apresenta o bombardeio de informações na vida cotidiana, através dos meios de comunicação, tais como a internet, a televisão, cinema, fotografia e pela produção do design, são percebidos processos híbridos que geram e coordenam narrativas e imagens esquizofrênicas. Tudo acontece simultaneamente, carregando ambiguidades, heterogeneidades e contradições. A pintura mesmo sendo um meio mais tradicional pode dialogar com essas questões.

O design e a pintura possuem características híbridas, combinando diferentes elementos, práticas e procedimentos para se representar questões variadas, articulando assim imagens e signos. A imaginação gráfica acaba interferindo no modo como as informações são dispostas e organizadas no cotidiano, por meio da justaposição e sobreposição de informações e da colagem, contaminando inclusive a percepção que temos do mundo.

Tratando especificamente a representação de paisagem na pintura, por meio do imaginário gráfico são produzidas imagens que dialogam com o entorno, com aquilo que é vivido no cotidiano. Este modo de se pensar a imagem, relacionando design e pintura, rompe com cânones de representação, estabelecidos principalmente no Renascimento, e geram outras formas de se pensar a paisagem.

Tanto na produção em design quanto na de pintura há o pensamento de uma época, no modo como as informações são tratadas e organizadas por meio de diferentes tecnologias, manuais e digitais. $\mathrm{O}$ que ocorre é que os diferentes meios expressivos acabam dialogando com a cultura digital ou cibercultura em que a produção visual é mediada por tecnologias e comunicações digitais. Contudo mesmo as práticas mais tradicionais, tais como a pintura, não deixam de existir, mas também podem ser pensadas de outras maneiras.

O design gráfico está presente nas práticas cotidianas e assim como sofre interferência das artes visuais, também acaba interferindo nos seus processos e no modo de compreensão das imagens, na possibilidade de entrecruzamento delas por meio de diferentes ferramentas, do manual até o digital. Enquanto no design são geradas inúmeras imagens que acabam tendo uma sobrevida devido a velocidade dos acontecimentos, na pintura essas mesmas imagens acabam apresentando um outro tempo, que pode se dar no próprio processo manual de feitura como também na permanência.

\section{Referências}

BENJAMIN, Walter. Benjamin e a obra de arte: técnica, imagem, percepção. Rio de Janeiro: Contraponto, 2012.

BURKE, Peter. Testemunha Ocular: História e Imagem. São Paulo: Editora Unesp, 2017.

CAMPOS, Marcelo. Luiz Zerbini. Disponível em: <http://fdag.com.br/app/uploads/2017/05/campos-marcelo-luiz-zerbini-2017.pdf>. Acesso em 5 ago. 2017.

CAUQUELIN, Anne. A invenção da paisagem. São Paulo: Martins, 2007. 
Conceito de Cultura Digital. Disponível em: http://culturadigital.br/conceito-de-cultura-digital/. Acesso em: 25 de março de 2018.

DENIS, Rafael Cardoso. Uma introdução à história do design. São Paulo: Edgard Blücher, 2002.

GARCÍA CANCLINI, Néstor. Culturas híbridas: estratégias para entrar e sair da modernidade. São Paulo: Editora da Universidade de São Paulo, 2003.

GIANNOTTI, Marco. Breve História da Pintura Contemporânea. São Paulo: Claridade, 2009.

HALL, Stuart. A identidade cultural na pós-modernidade. Rio de Janeiro: DP\&A Editora, 2006.

HALL, Stuart. Cultura e Representação. Rio de Janeiro: PUC-Rio / Apicuri, 2016.

IWASSO, Vitor Rezkallah. O mundo de segunda mão: fotografia, colagem e processos digitais na prática da pintura. Dissertação (Mestrado) - Escola de Comunicações e Artes, Universidade de São Paulo, São Paulo, 2011.

LEMOS, André. Ciber-cultura-remix. Disponível em:

https://www.facom.ufba.br/ciberpesquisa/andrelemos/remix.pdf. Acesso em: 25 de março de 2018.

MACHADO, A. Repensando Flusser e as Imagens Técnicas, in MACHADO, A. O Quarto Iconoclasmo. Rio de Janeiro: Contracapa, 2001.p. 34 a 55.

MACHADO, Arlindo. Hipermídia: o labirinto como metáfora. In DOMINGUES, Diana. A Arte no Século XXI. São Paulo: Ed, UNESP, 1997. P. 70-78.

MACHADO, Arlindo. Pré- cinemas e pós-cinemas. Campinas: Papirus, 1997.

MARTÍN BARBERO, Jesús. Ofício de cartógrafo: travessias latino-americanas da comunicação e da cultura. São Paulo: Edições Loyola, 2002.

MORIN, Edgar. Introdução ao Pensamento Complexo. Porto Alegre: Ed. Sulina, 2005. 